\title{
The SABRE gene is required for normal cell expansion in Arabidopsis
}

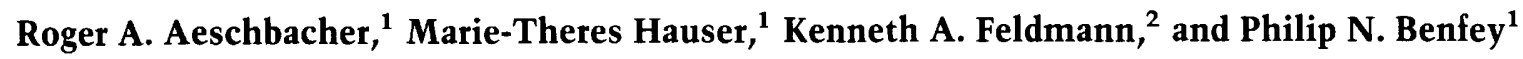 \\ ${ }^{1}$ Department of Biology, New York University, New York, New York 10003 USA; ${ }^{2}$ Department of Plant Sciences, \\ University of Arizona, Tucson, Arizona 85721 USA
}

\begin{abstract}
Regulated cell expansion is an important determinant of organ shape in higher plants. The sabre mutation results in abnormal cell expansion in Arabidopsis. There is a shift in the orientation of expansion evident primarily in root cortex cells. The $S A B R E$ gene has been cloned and found to encode a novel protein.

Reduction of effective levels of the plant phytohormone ethylene through use of inhibitors and an insensitive mutant resulted in partial rescue of the sabre phenotype. This suggested that one of the roles of SABRE is to counter the action of ethylene in promoting radial expansion in plant cells.
\end{abstract}

[Key Words: Cell expansion; cell shape; root morphogenesis; root development]

Received November 1, 1994; revised version accepted December 28, 1994.

Cell expansion is a key parameter of plant development. Because plant cells do not move in relation to one another, the direction and extent of cell expansion are critical determinants of the shape of plant organs. The genetic and molecular regulation of cell expansion is poorly understood in plants and other higher eukaryotes.

We have undertaken a genetic approach to understanding the control of cell expansion by isolating mutants with abnormal cell shape. We have focused our efforts on mutations that affect cell expansion in the root of Arabidopsis (Benfey et al. 1993). Abnormalities in cell expansion are easily identified in root tissue. Root growth is a continuous process in which a set of pluripotent initials in the root apical meristem give rise to progeny (Dolan et al. 1993; Aeschbacher et al. 1994; Benfey and Schiefelbein 1994). Cell division among these differentiated descendants is predominantly anticlinal, producing readily identifiable cell files. Most root cells expand so that their primary axis is parallel to the direction of root growth. This results in mature cells having the shape of long thin cylinders. Cells of the same tissue tend to expand to the same extent and are thus of similar size (Steeves and Sussex 1989). A major part of the expansion in the longitudinal orientation (which we will refer to as "elongation") occurs after most cell divisions have ceased so that there is a region of the root in which the primary morphological process is cell elongation. This region has been called the elongation zone (Steeves and Sussex 19891.

To identify mutations that affect cell expansion, we screened mutagenized plants for abnormal root formation. The sabre mutation results in plants that have short roots with an increased diameter. Initial characterization indicated that cell numbers had not been altered in the root but that radial expansion was abnormal (Ben- fey et al. 1993). We have isolated the $S A B R E$ gene and characterized the molecular lesions in three independently isolated alleles. Because the sequence of the encoded protein was novel, we investigated the gene's function by observing the phenotypic effect of agents that modify plant cell expansion.

The plant growth regulator ethylene has been shown to increase radial expansion of plant cells when applied exogenously (Abeles et al. 1992). Reducing the effective levels of ethylene in the sabre mutant either through use of inhibitors or in combination with an ethylene insensitive mutation caused a dramatic change in root cell shape resulting in partial rescue of the root phenotype. However, the sabre mutation does not result in significantly increased ethylene biosynthesis or sensitivity. We postulate a role for the SABRE protein in counteracting ethylene's ability to cause radial cell expansion. This provides evidence that cell shape can be determined by a dynamic equilibrium between factors that act in opposing directions. In the root, SABRE and ethylene appear to regulate two of these counteracting factors.

\section{Results \\ Three sabre alleles}

The sabre mutation was identified originally in a screen of $\sim 8000$ T-DNA-transformed Arabidopsis lines /Feldmann 1991\}, as a plant with abnormally expanded roots and stunted aerial organs (Benfey et al. 1993). Two other alleles of sabre were identified in a screen of an additional 6000 T-DNA-mutagenized lines. Heterozygous lines were crossed with each other, and the mutant phenotype was observed in $\sim 25 \%$ of the $F_{1}$ progeny. We analyzed the linkage of the mutant phenotype and the neomycin phosphotransferase (NPTII) gene carried by 
the T-DNA in the three lines. Tight linkage was observed for the first allele, sab1-1 (see Materials and methods). For the sab1-2 allele, of 440 mutant plants transferred to selective media, 8 were kanamycin sensitive. This indicated that there was linkage between the NPTII gene and the sab1-2 mutant phenotype but that the linkage was not tight enough to suggest that the phenotype was caused by insertion of the T-DNA. The mutant phenotype of the sab1-3 allele did not cosegregate with the NPTII gene.

The sabre mutation results in a shift in the orientation of root cortex cell expansion

The three sabre alleles exhibited very similar phenotypes. Previously, we had shown that the increased root diameter was the result of abnormal cell expansion. Measurements of cross-sectional areas indicated that the cortical cells expanded to a greater extent than other root cells (Benfey et al. 1993).

Optical sections of the sabre root revealed that cortical cells had undergone a shift in the orientation of expansion from the longitudinal to the radial direction (Fig. 1A). Epidermal and endodermal cells appeared somewhat abnormal, but the primary axis of expansion remained longitudinal (Fig. 1A). Vacuolation, which accompanies cell expansion, occurred closer to the root tip in sabre than in wild type (Fig. 1B). To further investigate the shift in orientation of expansion, we examined the location of nuclei in relation to the cell walls. In the mutant, nuclei in the cortex were located frequently adjacent to
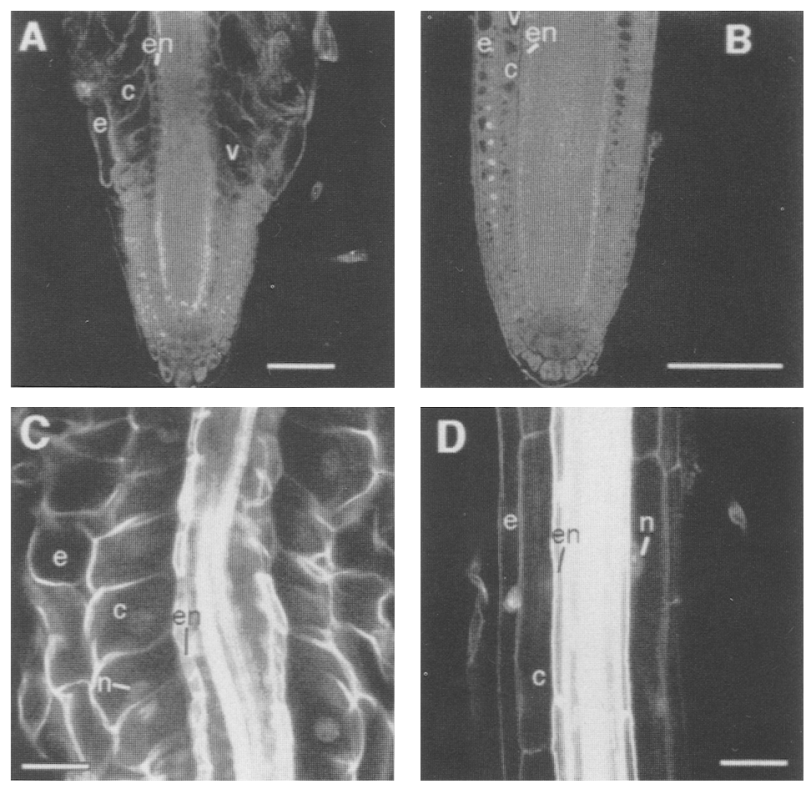

Figure 1. Optical sections of wild-type and sabre roots. Cytoplasmic contrast staining of root tips of sabre $(A)$ and wild type $(B)$. Acriflavine staining of roots of sabre $(C)$ on standard growth medium, and wild type on standard medium $(D)$. Bar, $50 \mu \mathrm{m}$. Abbreviations: (c) cortex; (e) epidermis; (en) endodermis; (n) nucleus; (v) vacuole. the transverse walls (Fig. 1C), whereas in wild type they were located along the longitudinal walls (Fig. 1D). In 118 mutant root cortex cells, $46 \%$ had nuclei adjacent to the transverse wall, $35 \%$ were found in the middle of the cell, and $19 \%$ along the longitudinal wall. In wild-type root cortex cells, the nuclei were consistently found along the longitudinal walls. We conclude that the sabre mutation results in a shift in the orientation of expansion in root cortical cells.

\section{The sabre phenotype is partially rescued by reducing ethylene levels}

Plant growth regulators have been shown to modulate cell expansion. Addition of exogenous ethylene causes enhanced radial expansion of root tissue (Jackson 1991; Baskin and Williamson 1992). Because we observed abnormal radial expansion of root cells in sabre, we were interested in the effect of compounds that inhibited the biosynthesis or action of ethylene.

sabre was grown for 9 days on nutrient agar media and then transferred to media that contained the ethylene biosynthesis inhibitor $\alpha$-aminoisobutyric acid (AIB). Under these conditions, radial expansion of the root was greatly reduced (Fig. 2A) and the roots were approximately twice as long as those left on growth media without the inhibitor (Fig. 2B). A similar effect was seen with addition of trans-cyclooctene (Fig. 2C,D) or silver ions $\left(\mathrm{Ag}^{+}\right)$(Fig. 2E), both of which inhibit ethylene action (Abeles et al. 1992). These effects were reversible. When transferred back to media lacking the inhibitors, there was a noticeable increase in the radial expansion of the mutant root (Fig. 2F).

At the cellular level, the effects of $\mathrm{Ag}^{+}, \mathrm{AIB}$, and transcyclooctene on sabre root cell expansion were similar. There was a marked reduction in the radial expansion of the cortical cells and a concomitant increase in elongation (Fig. 3A,B, cf. with Fig. 1C). Nuclei were now found located along the longitudinal walls (Fig. 3A,B). However, rescue of the sabre phenotype by these inhibitors was not complete as evidenced by a comparison with wild-type plants grown under normal conditions / $\mathrm{cf}$. Fig. 1D). In particular, the transverse walls of the cortical cells were still at an abnormal angle (Fig. 3A,B). Even though there was not complete rescue, measurements of cortical cell length indicated that there was a significant increase in cell elongation in the presence of the inhibitors (Table 1). The effect of the inhibitors on wild-type roots was a slight reduction in radial expansion and a slight increase in elongation (Fig. 3C).

We also analyzed the effect of increasing ethylene levels on expansion of cells in wild-type and sabre roots. Plants were grown on plates that contained the ethylene precursor 1-aminocyclopropane-carboxylic acid (ACC), production of which is the rate-limiting step in ethylene biosynthesis. The effect on wild-type roots was a reduction in elongation and an increase in radial expansion. Unlike sabre in which radial expansion was most pronounced in cortical cells when grown on normal media, in wild type grown on ACC, all cell types appeared to 


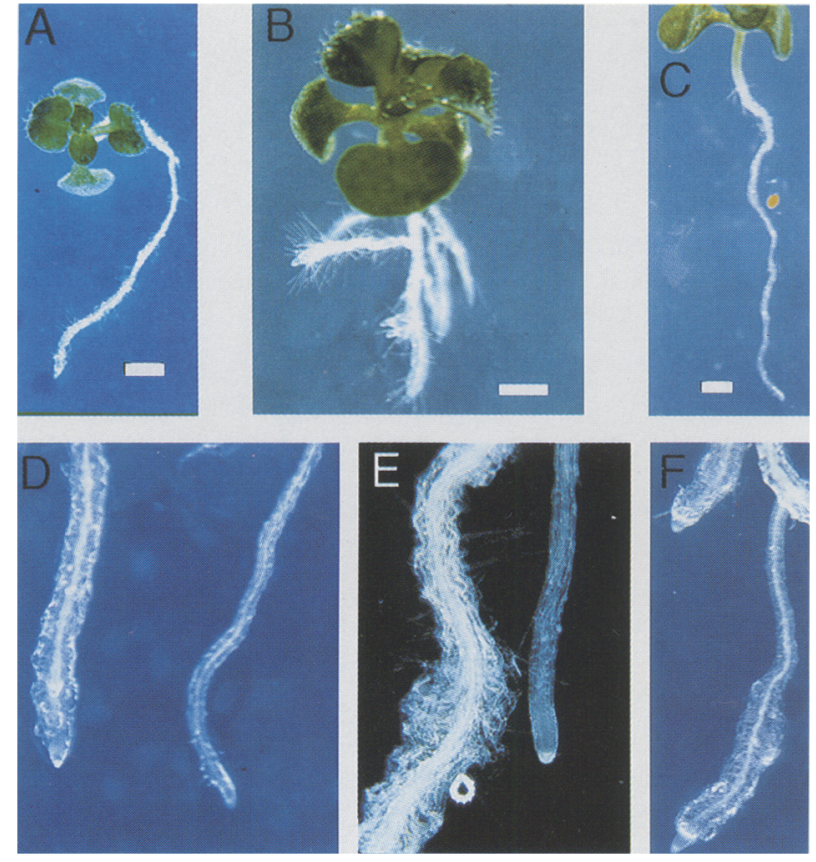

Figure 2. The effect of modulating ethylene levels on the sabre phenotype. $(A)$ sabre grown for 9 days on normal media and then transferred to media with AIB. $(B)$ sabre grown on normal growth media. $(C)$ sabre grown for 7 days on normal media followed by addition of trans-cyclooctene. (D) Roots of sabre grown on normal media (left) and media with trans-cyclooctene (right). (E) sabre grown for 9 days on normal media and then transferred to media with $\mathrm{Ag}^{+}$. Primary root at left developed while on normal media; secondary root at right developed while on media with $\mathrm{Ag}^{\prime} .(F)$ sabre grown in the presence of transcyclooctene and then transferred back to normal media. Bar, 1 $\mathrm{mm}$.

have approximately the same degree of enhanced radial expansion (Fig. 3D). Similar results have been reported previously for Arabidopsis roots grown in the presence of ethylene (Baskin and Williamson 1992). In sabre grown on ACC, the primary effect appeared to be enhanced radial expansion of epidermal cells (Fig. 3E).

\section{Combinations with ethylene response mutations alter the sabre phenotype}

To further analyze the effect of altering the ethylene response on cell expansion, we crossed sabre to mutants that had been shown to have abnormal ethylene biosynthesis or sensitivity. These mutants were isolated on the basis of the phenotypic response to ethylene known as the "triple response", which includes short roots, short and radially expanded hypocotyls, and increased curvature of the apical hook (Guzman and Ecker 1990).

The dominant mutant eto2-1 has been shown to have elevated levels of ethylene and is believed to be defective in the ethylene biosynthesis pathway /Guzman and Ecker 1990; Kieber et al. 1993|. In the $F_{2}$ progeny of a cross with sab1-1, 18 of 330 plants had the sabre mutant phenotype with roots that measured $4.33 \pm 1.29 \mathrm{~mm}$ at 10 days after germination. Another 39 plants exhibited a novel phenotype (Fig. 4A), with roots that were only $1.6 \pm 0.4 \mathrm{~mm}$ long. The phenotype of these plants was similar to sabre grown in the presence of ACC (Fig. 4B). Because Eto2-1 is a dominant mutation, the number of $F_{2}$ progeny with the novel phenotype was consistent with this being the double mutant. The putative double mutants were sterile precluding further genetic testing.

The constitutive triple response (ctr) mutant does not have significantly increased ethylene levels and is thought to be defective in the ethylene signal transduction pathway (Kieber et al. 1993). A novel phenotype was observed in the $\mathrm{F}_{2}$ progeny of the cross of sab1-1 with ctr1-5 (Fig. 4C) that was similar to the sab1-1, eto2-1 double-mutant phenotype. In this case, both mutations are recessive and the number of progeny with the novel phenotype was consistent with this representing the double mutant. The putative double mutants were again sterile, precluding further genetic testing.

In addition to these mutations that show increased ethylene biosynthesis or sensitivity, there are also mutants that have reduced sensitivity to elevated levels of ethylene (Bleecker et al. 1988; Guzman and Ecker 1990). The etr 1 (or ein 1) mutation is dominant and maps to a part of chromosome 1 (Chang et al. 1993) that is distal to the map position of sabre (described below). In the $F_{2}$ progeny of a cross between sab1-1 and ein 1-1, a novel phenotype was observed. Roots were longer and less expanded than sabre (Fig. 4D). Optical sections of the roots indicated that the cortical cells were longer and less radially expanded than homozygous sabre (Fig. 3F). The root cells resembled closely those of sabre roots grown on ethylene inhibitors (cf. with Fig. 3A,B). Measurements confirmed that there was a significant increase in cortical cell length in the putative double mutant (Table 1). The number of plants observed with the novel phenotype (27 of 236 total) was consistent with linkage between the sab and ein 1-1 loci. Because ein 1-1 and sab1-1 were in different ecotypes, we were able to use molecular markers to confirm that the novel phenotype cosegregated with the presence of the correct parental markers (see Materials and methods). In addition, we selected $F_{2}$ plants that had the ein phenotype (lack of response to ACC) and screened the $F_{3}$ progeny. Among these we identified a line that segregated $1: 3$ for the novel phenotype (Fig. 4E). Molecular markers indicated that a recombination event had occurred such that the $\mathrm{F} 2$ parent was homozygous for the ein 1-1 mutation and heterozygous for sabre. The molecular and genetic data support our conclusion that the novel phenotype arises from the combination of the $s a b$ and ein 1 mutations.

\section{Reduction of ethylene levels has no effect on the aerial phenotype}

A striking feature of the aerial phenotype of sabre was short wide leaves (Fig. 4F). The petiole was also shorter 

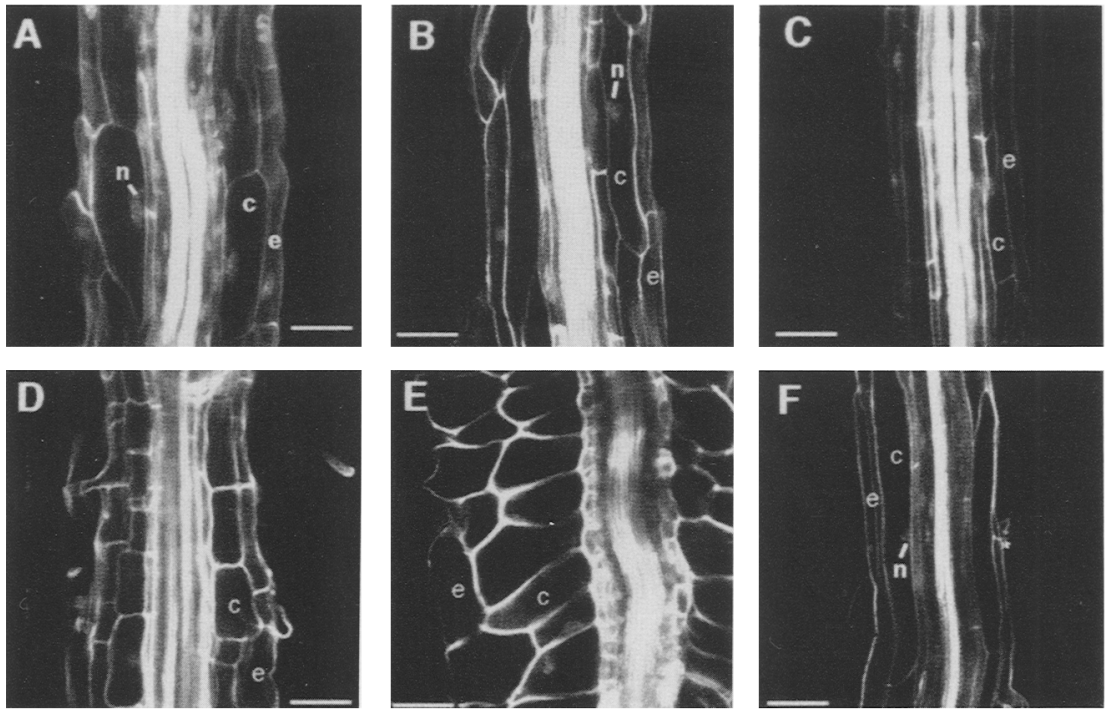

Figure 3. Optical sections of wild-type and sabre roots under different growth conditions. (A) sabre on media with AIB; (B) sabre in the presence of trans-cyclooctene; $(C)$ wild type on media with AIB; $(D)$ wild type (WS) on media with ACC; $(E)$ sabre on media with ACC; $(F)$ double mutant sab1-1, ein1-1 on standard media. Bar, $50 \mu \mathrm{m}$. Abbreviations as in Fig. 1. and wider than wild type. Mature mutant leaves closely resembled wild-type leaves that were just beginning to expand. Mutant cotyledons were also shorter and wider than wildtype. The mutant hypocotyl was shorter than wild type, and there was slightly increased radial expansion. Mutant flowers had the normal number and arrangement of organs, but the sepals and petals were shorter and wider than wild type. The carpel was also shorter than wild type and had an increased diameter.

We were unable to detect any change in the aerial phenotype when sabre was exposed to ethylene inhibitors. There were no detectable differences in leaf shape or hypocotyl length in mutant plants grown on normal media or in the presence of the ethylene inhibitors (Fig. 2, cf. A and B). The aerial phenotype of the double mutant sab11, ein 1-1 was also indistinguishable from that of the homozygous sabre phenotype (Fig. $4 \mathrm{H}$ ).

We performed an experiment to determine whether the leaf phenotype was caused by impaired root function. We induced callus formation and caused leaves to regenerate from the callus. Leaves of sab1-1 that had regenerated from callus had the same altered phenotype as leaves from mature sabre plants (Fig. 4G). We conclude that the $s a b$ mutation is responsible for the altered leaf phenotype but that reducing effective ethylene levels does not rescue this aspect of the phenotype.

Table 1. Length of root cortex cells

\begin{tabular}{llll}
\hline $\begin{array}{l}\text { Wild type } \\
(\mathrm{Col} ;\end{array}$ & $\begin{array}{l}\text { sab } \\
\text { (normal media; } \\
\mu \mathrm{m})\end{array}$ & $\begin{array}{l}\text { sab } \\
\text { (+TCO; } \\
\mu \mathrm{m})\end{array}$ & $\begin{array}{l}\text { sab, } \\
\text { ein1-1 } \\
(\mu \mathrm{m})\end{array}$ \\
\hline $175 \pm 38$ & $72 \pm 33$ & $147 \pm 45$ & $166 \pm 52$ \\
\hline
\end{tabular}

Measurements were made from median longitudinal optical sections made with a confocal scanning laser microscope. Measurement was along the cell wall that adjoins the endodermal cell layer.
The sabre phenotype is not the result of increased ethylene biosynthesis or sensitivity

Reduction of effective ethylene levels through growth on ethylene inhibitors or in combination with an ethyleneinsensitive mutation produced a partial rescue of the $s a b$ phenotype. This raised the possibility that the primary defect in sabre might be an increase in ethylene biosynthesis or sensitivity.

To test whether there was increased ethylene biosynthesis or sensitivity in the sab mutant, we looked for physiological manifestations of increased ethylene expression or sensitivity. As mentioned above, the extent of curvature of the apical hook in etiolated plants is sensitive to ethylene levels. The eto and ctr mutants have enhanced hook curvature as do wild-type seedlings grown on ACC (Kieber et al. 1993). In contrast, sab1-1 plants germinated in the dark showed apical hook formation (Fig. 4I) that was frequently less pronounced than in wild-type plants (Fig. 4J). The number of root hairs has been shown to be increased by application of exogenous ethylene (Baskin and Williamson 1992; Dolan et al. 1994). Ectopic root hairs were also observed in the ctr mutant (Dolan et al. 1994). In sab1-1 we did not observe the presence of ectopic root hairs.

In addition to the physiological evidence that the sabre phenotype is not the result of increased ethylene production or sensitivity, we analyzed a molecular marker for increased ethylene levels. Basic chitinase mRNA is induced upon exposure to ethylene (Samac et al. 1990). Induction is strongest in shoots and rosette leaves. Root tissue expresses higher basal levels of basic chitinase, and ethylene addition results in only a low level of induction (Samac et al. 1990). It has been shown that the eto and ctr mutants constitutively express this gene (Kieber et al. 1993). Basic chitinase therefore provides a useful indicator for changes in ethylene biosynthesis or sensitivity. Northern blot analysis indicated that the RNA levels of basic chitinase are undetectable 
Figure 4. (A) Putative double mutant sab1-1, eto2-1; $(B)$ sab1-1 grown on media containing $\mathrm{ACC} ;(C)$ putative double mutant sab1-1, ctr1-5 (middle), flanked by $s a b$ (left) and ctr (right); $(D)$ double mutant sab1-1, ein1-1 (left), sab1-1 (right); $(E)$ roots of double mutant sab1-1, ein1-1 (right), segregating from an $\mathrm{F}_{3}$ line, next to wild type (left), and sab1-1 (middle); $(F)$ mature leaves of wild type (left) and $s a b$ $($ right $) ;(G)$ leaves formed from calli of wild type (left) and sab (right); $(H)$ aerial phenotype of sab1-1 (left) and double mutant sab1-1, ein1-1 (right); $(I)$ apical hook of sab grown in dark for 4 days; $(J)$ apical hook of wild type grown in dark for 4 days. Bar, 1 $\mathrm{mm}$.
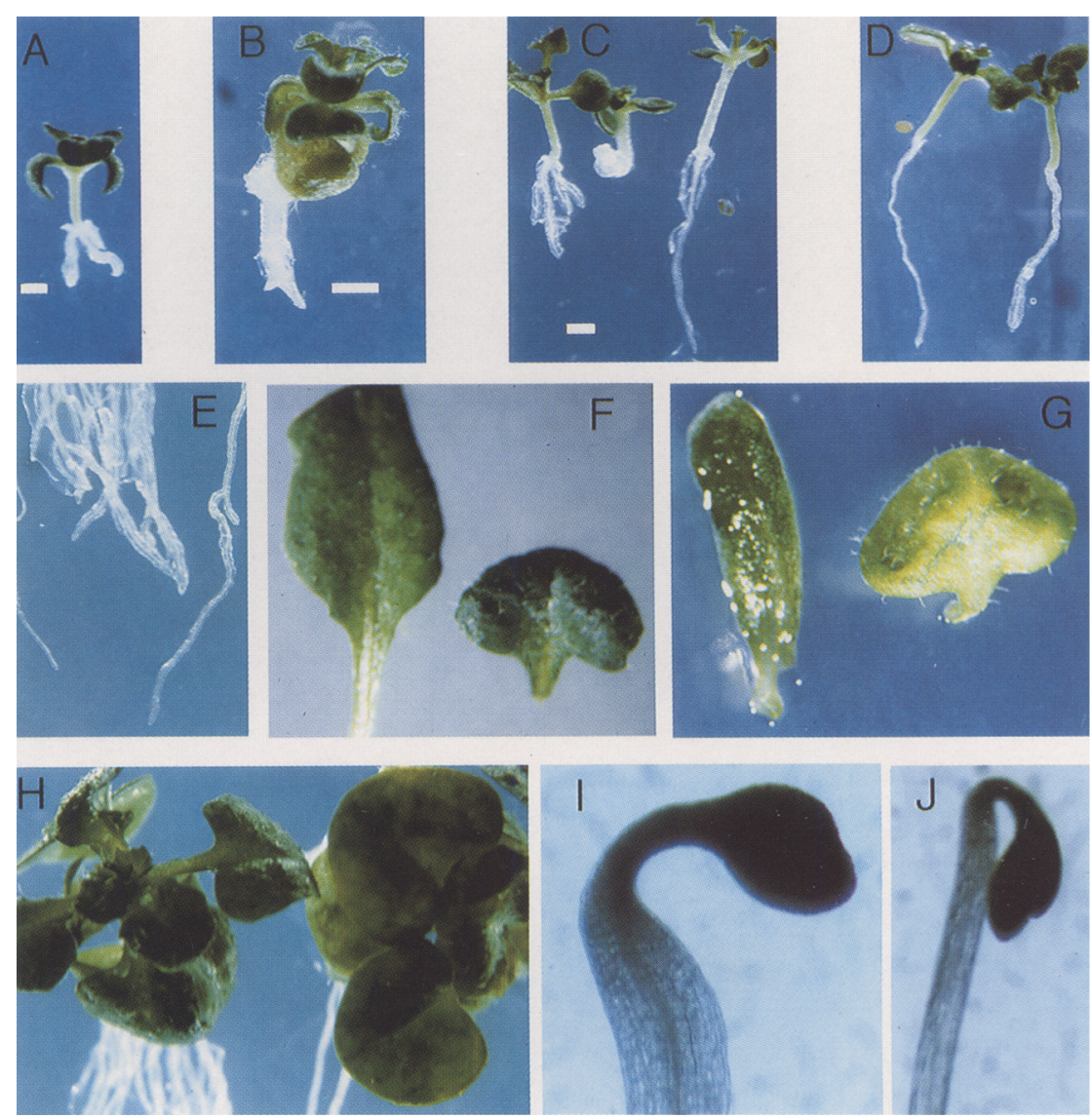

in the upper part of young seedlings of both sab1-1 and wild-type plants, whereas there was constitutive expression in the ctr mutant (Fig. 5). When grown on ACCcontaining media, basic chitinase RNA was induced in

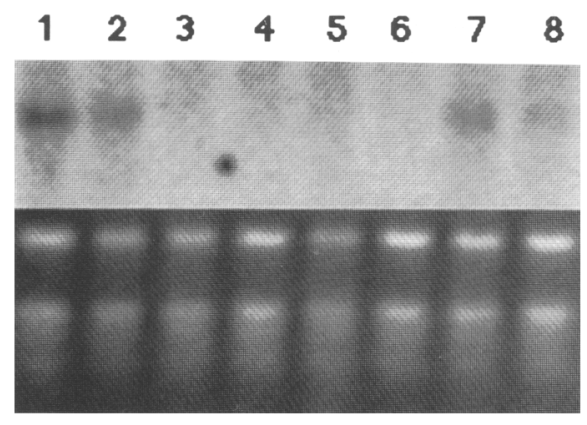

Figure 5. RNA blot analysis of expression of basic chitinase. Ten micrograms of total RNA from the aerial portion of seedlings was probed with basic chitinase cDNA. (Lane 1) ctr mutant on normal media; (lane 2) ctr mutant on AIB; (lane 3) sab1-1 on normal media; (lane 4) wild type on normal media; (lane 5) sab1-1 on media with AIB; (lane 6) wild type (WS) on media with AIB; (lane 7) Sab1-1 on media with ACC; (lane 8) wild type on media with ACC. Below the image of the autoradiograph is an image of the ethidium bromide-stained gel indicating approximately equal loading of the lanes. both sabre and wild type (Fig. 5). Because ethylene is gaseous, high levels of ethylene, even when produced locally in roots, should manifest themselves by an induction of basic chitinase in the aerial part of seedlings. We conclude from these analyses that there was no major change in ethylene levels or sensitivity caused by the sabre mutation.

We also analyzed the phenotype of sabre mutants that were grown on media that contained increased auxin, cytokinin, gibberellic acid, and abscissic acid as well as the auxin transport inhibitor 2,3,5-triiodobenzoic acid (TIBA) and the gibberellic acid biosynthesis inhibitor ancymidol. No dramatic change in root cell expansion or aerial phenotype was observed with any of these compounds. Other phenotypic changes did occur, but these were similar to those observed in wild-type plants (e.g., increased lateral root initiation on auxin).

\section{Isolation of the sabre gene}

Southern analysis of the progeny of heterozygous sab1-1 plants indicated that there was a complex arrangement of T-DNA but that it segregated as a single locus (data not shown). Plant sequences flanking the T-DNA were isolated from a genomic library made from the mutant and used to identify wild-type genomic and cDNA clones (see Materials and methods). One 12-kb genomic 
clone, pGRS2, was used to map the sabre mutation by detection of restriction fragment length polymorphisms (RFLPs) in recombinant inbred lines (Reiter et al. 1992). Linkage was found on chromosome 1 at a position between the markers g4026 and IAt213.

A 12-kb insert from pGRS2 was used to screen cDNA libraries. No hybridizing plaques were found in a library made from adult tissue. We then screened a library made from green siliques. Four positive clones were isolated from $\sim 2 \times 10^{6}$ screened. These represented overlapping sequences that mapped to $\sim 7 \mathrm{~kb}$ of the genomic region. Sequencing these clones revealed an open reading frame of $\sim 4 \mathrm{~kb}$ (Fig. 6A). From a high-molecular-weight fraction of a library prepared from etiolated seedlings, an additional $2 \times 10^{6}$ plaques were screened and four additional clones were isolated. These were partially sequenced, but none of them extended the $5^{\prime}$ region of the sabre cDNAs farther upstream.

The low frequency of sabre cDNAs in these libraries indicated that $S A B R E$ encoded a rare message. This was confirmed by Northern analysis with total and poly(A) RNA from aerial and root tissues in which no signal was detected after long exposures. Reverse PCR was used to amplify sabre cDNA with specific primers derived from the cDNA sequence. The number of cycles required to achieve detectable amplification provided additional evidence of very low-level expression (see Materials and methods). Amplification of $S A B R E$ mRNA was achieved from RNA of roots as well as shoots, though quantification was not attempted. Primers that spanned the T-DNA insertion site were able to amplify cDNA from wild-type RNA but not from sab1-1 RNA (data not shown). This suggested that the insertion had disrupted RNA expression.

The transcription start site was mapped using a method for rapid amplification of $5^{\prime} \mathrm{cDNA}$ ends (RACE) (Frohman et al. 1988). The RNA start site determined in this manner matched the consensus sequence (CAT; Kozak 1984; Fig. 6A). A potential TATA box was present at a distance of $27 \mathrm{bp}$ from this site (Fig. 6A). The ATG codon at position 95 is the beginning of the longest open reading frame and is the probable translation start site (Fig. 6A). All other reading frames contained multiple stop codons. There were two short open reading frames that began at positions 15 and $42,5^{\prime}$ to the predicted start codon. Both were terminated at position 75. A possible consensus sequence for polyadenylation (AATAAA) was found at position 4134 (McLauchlan et al. 1985). The sequence of $2640 \mathrm{bp}$ of the $5^{\prime}$ upstream region was also determined (Fig. 6A).

The structure of the $S A B R E$ gene was determined by amplifying and sequencing fragments using primers deduced from the cDNA sequence (Fig. 6B). The T-DNA insertion of $\sim 40 \mathrm{~kb}$ in $s a b 1-1$ was located in the middle of the third intron (Fig. $6 \mathrm{~B}$ ). To determine the molecular lesions in the other two alleles, Southern blotting was performed on genomic DNA using subclones from the wild-type genomic region as probes. A deletion of $\sim 1.2$ $\mathrm{kb}$ was detected in the genomic region around position 2830 of sab1-3 (Fig. 6B). No major structural alteration was detected in a $10-\mathrm{kb}$ region of the genomic DNA of sab1-2. This indicated that the T-DNA that was linked to the locus was not in its immediate proximity as would be predicted from the cosegregation data. Primers used to determine the wild-type genomic structure were used to amplify and sequence the genomic DNA of the sab1-2 allele. A 1-bp deletion in sab1-2 was detected at position 326 (Fig. 6B). This induced a frameshift in the reading frame, and the deduced protein was terminated at position 330. These molecular lesions in the three alleles provide strong evidence that we have cloned the SABRE gene. The nature of the lesions in combination with the very similar phenotypes suggests that all three alleles produce a null phenotype.

\section{The sabre gene encodes a novel protein}

The deduced sequence of the SABRE protein is 1347 amino acids long, and the predicted molecular mass is $154 \mathrm{kD}$. The complete protein as well as multiple overlapping fragments were compared to sequences in the protein data bases. No significant homology was found. Searches for structural motifs revealed no evidence for transmembrane spanning domains or other motifs strongly suggestive of function. The deduced sequence predicted a rather hydrophilic protein. Encoded at positions $1105-1110$ is the sequence SHEEKK, which is repeated at positions 1114-1119. The function of this highly charged sequence is unknown. Another region with stretches of highly charged residues is at amino acid positions $723-783$ in which 24 of 61 residues are acidic and 8 are basic.

To identify sequences in other plant species that may be related, a Southern blot with DNA from various plants was hybridized under low stringency with a $S A$ $B R E$ cDNA probe. Hybridization was observed in rice, barley, and tobacco indicating that there were conserved sequences in monocots as well as other dicot species (Fig. 7). A single hybridizing band was observed for Arabidopsis DNA indicating that this represents a unique sequence in the Arabidopsis genome.

\section{Discussion}

\section{Regulation of plant cell expansion}

Little is known about the genetic regulation of plant cell expansion. In fact, there is little known about the genetic regulation of cell expansion in any eukaryote. Mutants in yeast with abnormal shapes have been isolated (Snell and Nurse 1993), and in Drosophila, genes have been identified that regulate invagination during gastrulation (Leptin 1994). The Arabidopsis root provides an ideal system in which to study cell expansion. The continuous formation of cells in the meristem and their highly regulated expansion as they progress through the elongation zone make this a system in which abnormal cell expansion can be easily identified and characterized.

We have shown that the sabre mutant has abnormal root cell expansion. The defect appears to cause root cor- 
Aeschbacher et al.

A

2640 GAATCAAAGCTATCGTGCTGTACATCTCATTATTTGTATCTTGTACTAGATAATATCTGATTTAGTTTGTCTAAATTAGTCTTTATATATTAACAGAACTTAATCTGTAGTTGTGAGAT -2520 AGGCCAAAACTTTCACATCATGATTGTTTAGTTCTTTATTTTGCTGGCAACATATGAATTGGTTTTACTAGGA TGTTAAACACTCTTTTTYTTTTTGCTTGGTGTAATATATGCAGTTTTT TCACAGTCATCACATGTGTTTGCAAATAACGTTTCGAGTCTGGGCACAGCAGTTCATGTTGAACTTGGTGACTGAATCTGCATTTGGCAGA TGAGTACCAAGAATGC TTTAGAGAACA $-2280$

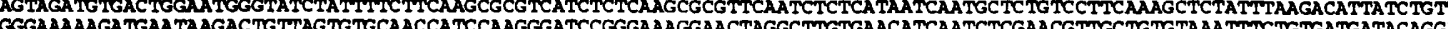
ACTGGGAAAAGATGAATAAGACTGTTAGTGTGCAACCATCCAAGGGATCCGGGAAAGGAACTAGGCTTGTGAACATCAATCTCGAACGTTGCTGTGTAAATTTCTGTGATGATACAGGA CCTGAAGCTTGTAAAAGACTGAAGTACTCAGTCTCTCTTGAAATATCACAGTTTAGCTITTGTCTCAACAAGATAAACTCTCAACTCAAATGGACTTGGAAGGCAAAATCCATCTAC CAGGAGTATCTGGAAGAACATACGCCTTGTTCGAATGTCATATIGTTTGATATGCACAATGCTAAGCTTGTACGTCGATCCGGTGGTCTTAATGAAATTGATGTCTGTTCTCTCTTCAGT GCTACTCATATTTCGCTGGGTTGGGAACCTGACGTCCATCTATCTTTTTATGAACTGTTTTTACGTTTGAGATCCCTGGTGTATGCACAAAGGCA TAAAGAACCTGAAAGCGGGTGCAAT AAAGGCATCTCTAGTGTGAAAGATGGTGGCCCGAGTGAAAAAATAAATCAATCCAATTCTGTTAACAAGCAGAAGAAAAAGGAATCTATGTTTGCTATTGATGTGGAAACGTTGACTATT TTTAAAACTACAAGAATGCAAGTATCAAGAATCCCTACTGCTACGAATTTGTCTGATGCAGTCCCTGTAATGACAGATGGTCCTTGGGACTGGGTAGTACAAGGACTTGACGTGCA TA T TGTATGCCATACAAACTGCAGTTGCGTGCCATAGA TGATTCAATAGAAGAGATGTTGCGAGGCTTGAAACTTATATCTGTAGCAAAGGGAAACA TATTTTATCAGGAAAGAGAGAAAGC TCAAAGCCTAAGAAATCTAGTCCAAAATTTGCCGCATAAGATTTTCATACGCAGACTAACCGCAGATATTGAGGAAGAACCAATTCAGGGCTGGCTTGATGAACACTATCAGCTGGTG AAGAAAGAGCCTGCGAGTTGGCTGTCAGATTGAATTCCTTGAAGATTTGATTCACAAAGCTGGTCAGTCTCCTAAAGGGCAGAAACAAGTGCTGTATTAGATGAGAGAAAGATGTT

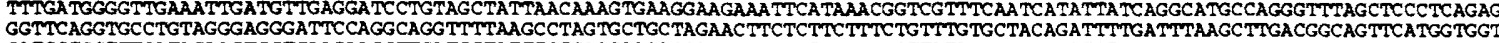
GGTTCAGGTGCCTGTAGGGAGGGATTCCAGGCAGGTTTTAAGCCTAGTGCTGCTAGAACTTCTCTTCTTTCTGTTTGTGCTACAGATTTTGATTTAAGCTTGACGGCAGTTCATGG TGG TTAAGAAATTATACACTTCCTCTCCTCTCTGGCACTTCTGGCAAATGTGAAGGTCGTATTGTACTGGCTCAGCAGGTATTGTTATTTTCTTGTTTTCTTTTCCATGCCATCTGTGGTAGG GTGTAAATCAATAATCTCTCCTGTTCTCTAA TTCAAGCA TGTTGATCTCAATTAAATGATTATTTGACTGC TTGTTACTGTTTTTCTTAAAC TAGGCAACATGTTTCCAACCACAAATTTV

1 ITTGGGGTGGATATGAACCAGCTTTGCAGACATTAGCTATGCCTTTACAGTGGCTCTTCGTAGAGCTAATCTAAGTCATAGGAATCCAGATATGGTACAAGTCATTAAAAAAGACG

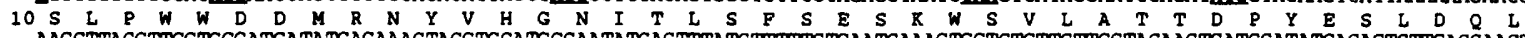
120 AAGCTTACCTTGGTGGATGATATGAGAACTACGTCCATGGCAATATCACTTTATCTTTTTCTGATCAAAGTGGCTGTTCTTGCTACACTGATCCATATGAGAGTCTTGACCAACT

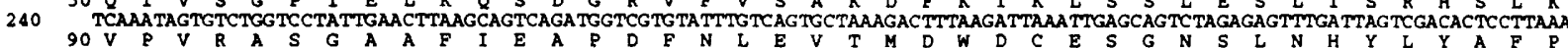
360 AGTTCCAGTCCGCGCTTCCGGAGCTGCATTTATTGAAGCCCCAGATTTTAATCTTGAAGTTACAATGGACTGGGATTGCGAATCTGGGAATTC TTTGAATCATTATCTCTATGCATTTCC

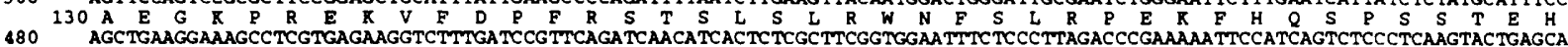

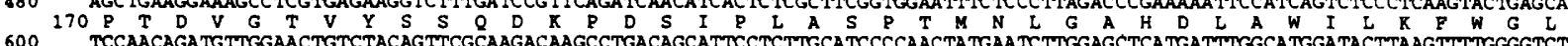

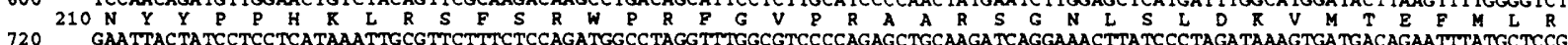

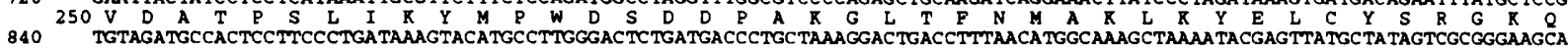

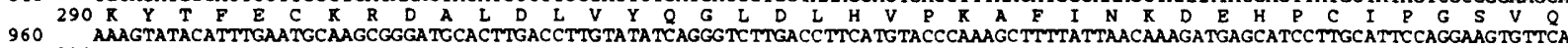

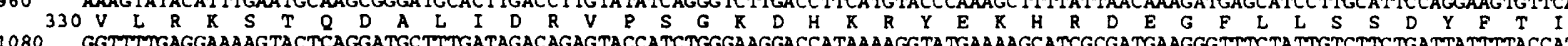
1080 GGTTTMAGGAAAGTACTCAGGATGCTTTGATAGACAGAGTACCATCTGGGAGGACCATAAAAGGTATGAAAGCATCGCGATGAAGGGTTMCTATTGTCTTCTGATTATTTTACCAT $1200{ }^{370} \begin{gathered}\mathbf{R} \\ \text { CAGAAGGCAGGCCCCAAAAGCAGATCCTGAAAGACTATTGGCATGGCAAGAGGCTGGAAGAAGAAATCTTGAGATGACATATGTACGGTCTGAGTTTGAGAATGGAAGTGAGAGTGATGA }\end{gathered}$ 1320 ACACATACGATCAGATCCTAGTGATGATGACGGGTACAATGTTGTATTGCTGACAACTGTCAGCGGTCTTTGTTPACGCCTCAAACTCCTGTGGACGATAGAGAACAGGGATGCTGT 1440 TTGGTCTTITGTTGGTGGAATATCAAAAGCATTTGAACCTCCTAAACCTTCTCCTTCTCGTCAGTATACTCAGAGGAAGATTCATGAAGAAAACCAAAAGGAATCTTGTCCAGAAACGCA

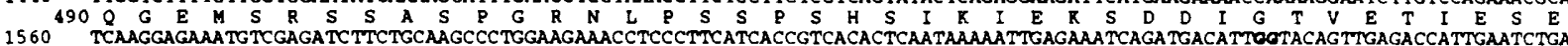

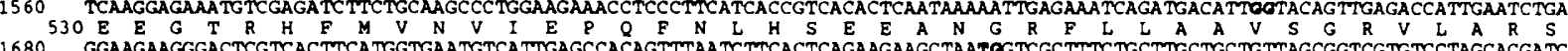
1680 GGAAGAAGGGACTCGTCACTTCATGGTGAATGTCATTGAGCCACAGTTTAATCTTCACTCAGAAGAAGCTAATOGTCGCTTTCTGCTTGCTGCTGTTAGCGGTCGTGTCCTAGCACGATC

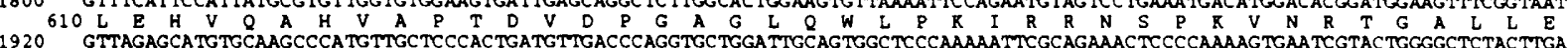

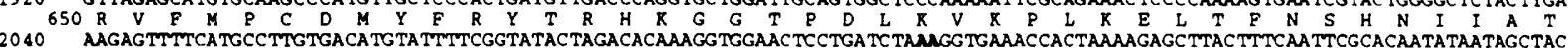

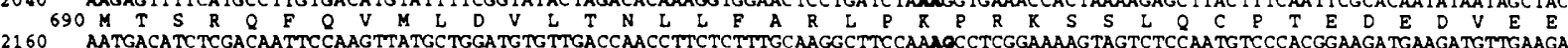

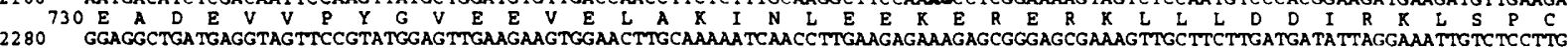

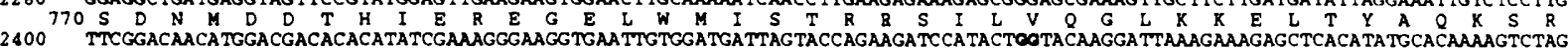

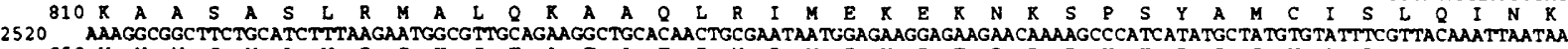
$2640^{850}$ AGTTGTTTGGAGCATGCTTGTAGATGGTAAATCCTITGCTGAGGCAGAGATAAATGACATGATTTATGACTTTGATCGGGACTACAAAGACATTGGTGTTGCTCGATTCACCACCAAGTA

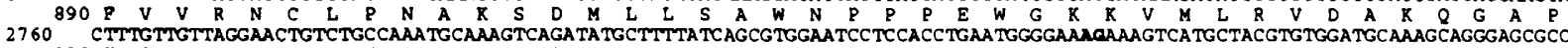

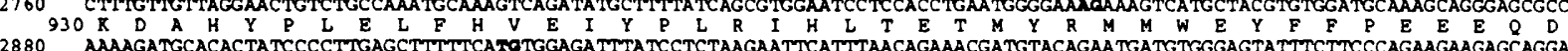
2880 AAAAGATGCACACTATCCCCTTGAGCTTTTTCATOTGGAGATTTATCCTCTAAGAATTCATTTAACAGAAACGATGTACAGAATGATGTGGGAGTATTTCTTCCCAGAAGAAGAGCAGGA

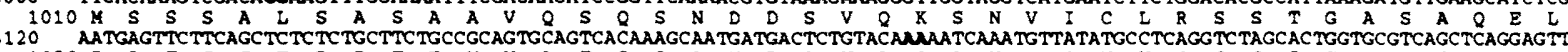

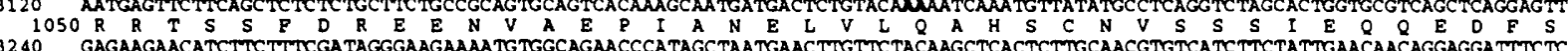
3240 GAGAAGAACATCTTCTTTCGATAGGGAAGAAAATGTGGCAGAACCCATAGCTAATGAACTTGTTCTACAAGCTCACTCTTGCAACGTGTCATCTTCTATTGAACAACAGGAGGA TTTCTC

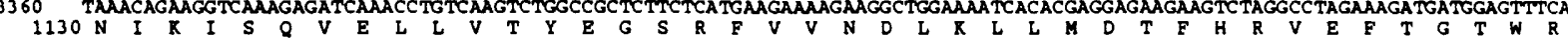
3480 CAACATTAAATTAGTCA COTGGAGCTICTAGTTACTTATGAGGGTCAAGATTIGTIGTAAATGACCTCAAATTGTTGATGGATACATTTCATCGTGTTGAGTTTACCGGGACTTGGAG

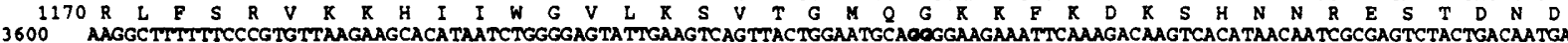

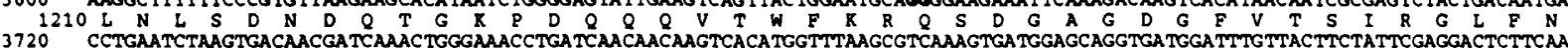

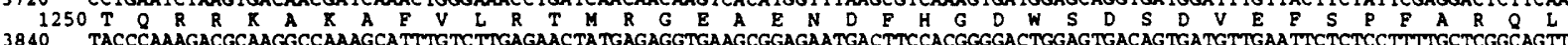
3840 TACCCAAAGACGCAAGGCCAAAGCATTTGTCTTGAGAACTATGAGAGGTGAAGCGGAGAATGACTTCCACGGGGACTGGAGTGACAGTGATGTTGAATTCTCTCCTTTTGCTCGGCAGTT 3960 AACTATTACAAAAGCTAAGAGACTCATCAGACGTCACACTAAAAAATTCGTCCAAGATCTCAAAGACOTTCAACATCTCAGCAAAGAGAATCACTTCCATCATCTCCAATAGAGACCAC $1330 \mathrm{P} F \mathrm{E} S \mathrm{G}$ Y S S G S S P Y E D E R E

4080 TCCATTTGAAAGTG TITTCAAGTGGATCTTCACCATACGAAGATTTTCGGGAJAAAAACTCATTCTGACCAAATTTTGTATCAAGGGTAAATAGGAAAGGAAAAAGGTATATTA 4200 GAGAGAGAGTGACAATATTGTACAGAGGTATATTGGAGTATAAATTAAAATCAACAAAGCTTAATAGAGTGTGCCTTGTCGGCAAATTTGCAAATAGAAAAGCTTCAAGTCCATGTCCT 4320 TGAACTTACTGAAGCGCTCAAAATAACAATTATCTTCGATTTTTTTAAAAAAGATTAAACAATAGATTTTGCTTTCTGGCATGGGAATCCATA

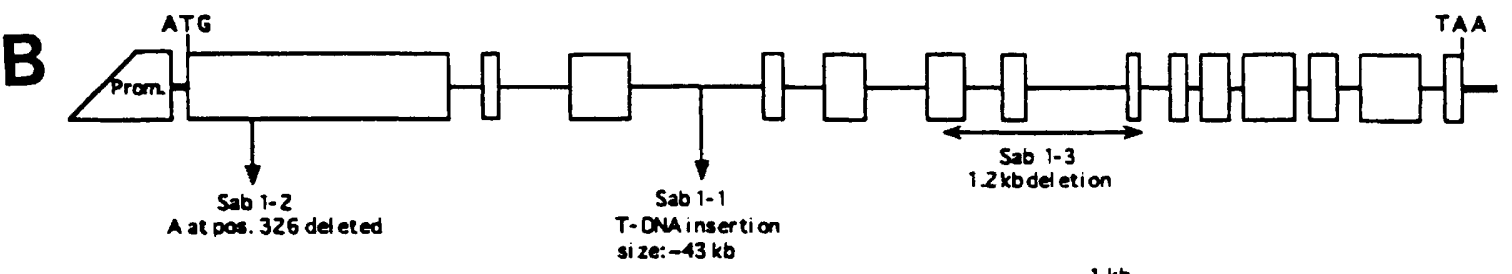

Figure 6. (See facing page for legend.) 


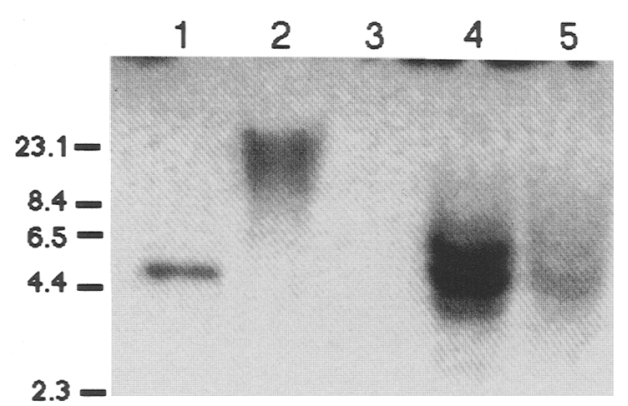

Figure 7. Southern blot analysis of monocot and dicot species DNA. Approximately $10 \mu \mathrm{g}$ of DNA was digested with EcoRI and hybridized with a fragment of $S A B R E \mathrm{cDNA}$. (Lane 1) Arabidopsis; (lane 2) tobacco; (lane 3) maize; (lane 4) rice; (lane 5) barley.

tical cells to shift their orientation of expansion. Our characterization of the $S A B R E$ gene revealed the molecular lesions in three alleles. The nature of the defects suggested strongly that all three alleles produced a null phenotype. The encoded protein is novel, and, therefore, we addressed the issue of function by modulating the levels of substances that are known to affect plant cell expansion. The only substances that were able to effect partial phenotypic rescue inhibit the biosynthesis or action of the plant growth regulator ethylene.

Ethylene affects many plant processes including fruit ripening, senescence, and abscission (Abeles et al. 1992). Ethylene has also been shown to have an effect on the orientation of cell expansion. Exogenously applied ethylene will cause decreased elongation and increased radial expansion in epicotyl and root cells (Jackson 1991; Abeles et al. 1992; Baskin and Williamson 1992). Growth of the sabre mutant on inhibitors of ethylene biosynthesis or action resulted in a dramatic shift in the orientation of expansion of root cortical cells. A similar effect was seen when the sabre mutation was placed in combination with a mutation that renders the plant at least partially insensitive to ethylene. Surprisingly, in neither case was there a detectable change in the aerial phenotype. Physiological and molecular evidence indicated that the primary defect in sabre was not abnormal biosynthesis or sensitivity to ethylene. In addition, growth on ethylene biosynthesis inhibitors has no effect on the expansion phenotype of six other mutants with abnormal root expansion (Hauser et al. 1995). The extent and direction of abnormal expansion vary among these mutants, but all have reduced elongation and enhanced radial expansion in at least one cell type (Hauser et al. 1995). Therefore, the ability to cause partial rescue by reducing effective ethylene levels is specific to the sabre expansion phenotype.

\section{Reasons for partial phenotypic rescue}

We have demonstrated that reduction of effective ethylene levels results in partial rescue of the sabre root phenotype. However, root cells are not normal when ethylene levels are reduced. In particular, the angles formed by transverse cell walls are frequently abnormal. In addition, reduction of ethylene has no apparent effect on the aerial phenotype. We interpret this to mean that there is an absolute requirement for the $S A B R E$ gene product to achieve normal cellular elongation, particularly in the aerial part of the plant. It remains possible that even lower levels of ethylene than those that we have been able to obtain through use of inhibitors or in combination with the ein 1 mutation may result in cells with a more normal appearance.

Another puzzling question is why the sabre mutation affects primarily cortex cell expansion in the root. The answer may lie in the structural constraints that direct plant cell expansion. The primary structural constraint that channels the direction of cell elongation is thought to be the cellulose microfibrils in the cell wall (Roberts 1989). The orientation of the microfibrils is thought to be directed by cytoplasmic microtubules (Giddings and Staehelin 1991). Microtubules in cortex cells may be particularly sensitive to changes in ethylene levels. In maize, ethylene was found to affect preferentially the orientation of microtubules in the outer cortex of the root (Baluska et al. 1993). However, in Arabidopsis no effect on microtubules in root cells was detected when plants were grown in ethylene (Baskin and Williamson 1992). An alternative explanation is that functionally redundant factors exist in other cells that could complement the lack of $S A B R E$ activity.

\section{The nature of the SABRE protein}

The sequence of the deduced SABRE protein provides little insight into its function. Whether the repeated SHEEKK sequence and other charged domains have a functional role awaits further analysis. However, the very low expression levels of $S A B R E$ mRNA and its lack of homology to known structural elements suggest that the $S A B R E$ gene does not encode a structural component. Instead, we propose that it plays a role in regulating cell expansion by facilitating elongation. To perform this role, it could be associated with microtubules or it may influence the orientation of cell expansion in a more indirect fashion. Our results also indicate that sabre is not in an ethylene pathway, rather its gene product

Figure 6. Sequence and structure of the $S A B R E$ gene. $|A|$ Combined sequence of four overlapping cDNAs and promoter region from genomic clone. The probable start site of translation is indicated with the deduced amino acid sequence. The probable start site of transcription is indicated, as is a putative TATA sequence. Positions of introns are in boldface type. (B) Structure of the $S A B R E$ genomic region. Exons are indicated as rectangles, and introns as lines connecting the exons. The positions of the molecular lesions in the three alleles are indicated. 
counteracts ethylene's ability to cause radial expansion, at least in root cortex cells.

We have shown that mutations in $S A B R E$ can dramatically alter cell shape. Reducing effective ethylene levels in a plant that is mutant for the $S A B R E$ gene can partially rescue the phenotype of some cells. Increased ethylene biosynthesis or sensitivity does not appear to be the primary defect in this mutant. To explain our results we postulate that $S A B R E$ gene activity is required for plant cells to attain their normal shape. One aspect of cell expansion that $S A B R E$ activity regulates involves a "dynamic equilibrium" between ethylene and the SABRE protein. This is presented schematically in Figure 8 . Under this hypothesis SABRE and ethylene produce opposite effects on root cell expansion. Raising ethylene levels causes the equilibrium to be shifted toward radial expansion. Wild-type SABRE protein resists this tendency and shifts the equilibrium toward elongation. In the absence of functional SABRE protein (as in the $s a b$ mutant), the equilibrium shifts toward radial expansion under normal levels of ethylene. Reduction of ethylene below wild-type levels through use of inhibitors or through combination with the ein 1 mutant shifts the equilibrium back toward elongation. This results in a more normal cell, but one that still exhibits defective cell expansion. According to this model, ethylene inhibitors do not complement SABRE but shift the equilibrium toward longitudinal expansion. The ein 1-1, sab1-1 double mutant is not simply a rescued mutant, it is a plant with root cells that resemble wild type. The wildtype cell shape is achieved by reducing SABRE levels to zero and at the same time reducing effective ethylene levels. A prediction of this hypothesis is that increasing the levels of $S A B R E$ in mutant or wild-type cells should cause increased elongation.

If this hypothesis is correct, it suggests a paradigm for one level of regulation of plant cell expansion. The extent or direction of cell expansion could be determined by the equilibrium between pairs of counteracting activities. Ethylene and SABRE would regulate one pair of activities that control the degree of radial expansion of

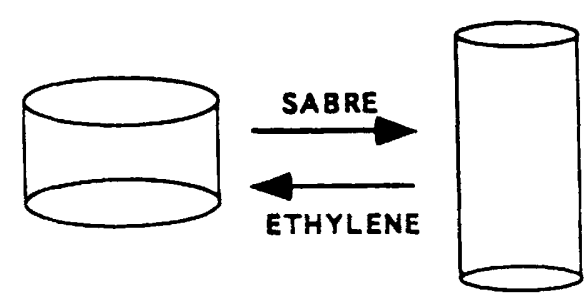

Figure 8. Dynamic equilibrium model of role of $S A B R E$ in regulation of cell expansion. In this model, SABRE protein is required for the cell to achieve normal elongation as shown schematically by the longer cylinder at right. Elevated ethylene levels cause the cell to become expanded more radially as depicted by the wider cylinder at left. In a sabre mutant and with normal ethylene levels, the cell is radially expanded. Lowering effective ethylene levels then pushes the "equilibrium" back toward elongation, resulting in more normal cell shape. root cortex cells. This is an important modification of the model that ethylene acts directly to vary the orientation of cortical microtubules that in turn regulate the orientation of cell expansion (Baluska et al. 1993).

\section{Materials and methods}

\section{Plant culture}

Arabidopsis seeds were surface sterilized and grown in Murashige and Skoog (MS) medium (Sigma) with $4.5 \%$ sucrose as described previously (Benfey et al. 1993). For the ethylene inhibitor studies, the following were added to MS medium: $2 \mathrm{mM} \mathrm{AIB}$ (Sigma), $0.5 \mathrm{~mm} \mathrm{ACC} \mathrm{(Sigma),} 5 \mathrm{mg} / \mathrm{l}$ of silver thiosulfate (freshly prepared from silver nitrate and sodium thiosulfate stock solutions). Trans-cyclooctene (5 $\mu$ l of $99 \%$ solution) was added to plates after 7 days growth. Regeneration of shoots from calli that had been induced from roots was according to the regeneration regime described in Valvekens et al. (1988).

\section{Genetic analysis}

Cosegregation of the mutant phenotype and kanamycin resistance conferred by the inserted T-DNA was determined by planting seeds on nonselective media. After 7-10 days, phenotypically mutant and wild-type plants $(\sim 500)$ were transferred to separate media containing $100 \mu \mathrm{g} / \mathrm{ml}$ of kanamycin. Approximately 10 days later, plants were scored for antibiotic resistance. Phenotypically wild-type plants were also transferred to soil and allowed to self-fertilize. Seeds were planted on media with and without kanamycin and scored for cosegregation of the mutant phenotype and kanamycin resistance. Complementation analysis was performed by using pollen from a phenotypically wild-type kanamycin-resistant (heterozygous) sab1-1 plant to pollinate several phenotypically wild-type $s a b 1-2$ or sab1-3 plants. The progeny of the sab1-2 and sab1-3 plants were analyzed for segregation of mutants indicating that they were heterozygotes. The progeny of the crosses of heterozygous plants were plated and scored for mutant phenotype. Crosses to ctr1-5 were performed in a similar manner. Crosses to ein 1-1 and eto2-1 used a heterozygous sab1-1 to pollinate homozygous ein1-1 and eto2-1. Kanamycin-resistant $F_{1}$ progeny were selected, and $F_{2}$ progeny produced by self-fertilization. $F_{2}$ progeny of the ein1-1, sab1-1 cross were planted on ACC-containing media and incubated in the dark for 4 days. Thirty-five plants that appeared insensitive to the effects of ethylene were transferred to soil and allowed to self-pollinate. $F_{3}$ progeny were screened for lines segregating the novel double-mutant phenotype. Microsatellite markers (Bell and Ecker 1994) were used to detect recombination events because ein 1-1 is in the Columbia ecotype and sab1-1 is in the WS ecotype. The marker ngall1 was used as evidence of linkage to ein1-1, and the marker nga280 was used as evidence of linkage to $s a b 1-1$ (Bell and Ecker 1994). DNA extraction was as described (Konieczny and Ausubel 19931, and polymerase chain reaction conditions were essentially as described (Bell and Ecker 1994). F2 progeny of crosses of sabre to wild-type Columbia ecotype segregated for the sabre phenotype and for the wild-type phenotype in ratios of $\sim 1: 3$.

\section{Confocal microscopy and image analysis}

Seedlings were fixed in FAA $150 \%$ ethanol, $5 \%$ acetic acid, $3.7 \%$ formaldehyde) at room temperature for $1 \mathrm{hr}$. After incubation with $15 \%$ ethanol for $30 \mathrm{~min}$, the seedlings were washed twice with $\mathrm{H}_{2} \mathrm{O}$. Permeabilization was accomplished by incubation at 
$60^{\circ} \mathrm{C}$ in $1 \mathrm{M} \mathrm{HCl}$. After washing once with $\mathrm{H}_{2} \mathrm{O}$, seedlings were stained for $1 \mathrm{hr}$ in a solution of $0.2 \%$ acriflavine (Sigma), $1 \%$ $\mathrm{K}_{2} \mathrm{~S}_{2} \mathrm{O}_{5}$ in $0.2 \mathrm{~N} \mathrm{HCl}$ at room temperature. Clearing and mounting was in a solution of chloral hydrate that was prepared by adding $100 \mathrm{ml}$ of $\mathrm{H}_{2} \mathrm{O}$ to 250 grams of chloral hydrate.

Cytoplasmic contrast staining was performed as follows: Seedlings were fixed in a solution of $4 \%$ paraformaldehyde, $5 \%$ DMSO, $0.1 \%$ glutaraldehyde, $50 \mathrm{~mm}$ PIPES, $5 \mathrm{~mm}$ EGTA, and 5 $\mathrm{mM} \mathrm{MgSO}_{4}\left(\mathrm{pH} \mathrm{7.0)}\right.$ by vacuum infiltration at $4^{\circ} \mathrm{C}$ for $1 \mathrm{hr}$. Seedlings were then washed three times in a solution of $50 \mathrm{~mm}$ PIPES, $5 \mathrm{~mm}$ EGTA, and $5 \mathrm{~mm} \mathrm{MgSO}_{4}(\mathrm{pH} 7.0)$ for $30 \mathrm{~min}$. Seedlings were then transferred to a solution of $2 \%$ driselase (Sigma) that was vacuum infiltrated for $1 \mathrm{hr}$ at room temperature for permeabilization. The seedlings were washed twice followed by a $10-\mathrm{min}$ incubation with $100 \%$ methanol at $-20^{\circ} \mathrm{C}$. Seedlings were washed twice then infiltrated for $15 \mathrm{~min}$ with $0.5 \%$ NP-40 in wash buffer. Seedlings were washed twice then incubated for $\mathrm{l} \mathrm{hr}$ at room temperature with 4 units of rhodamine-phalloidin (Molecular Probes) in $300 \mu$ l wash buffer with $2 \mathrm{~mm}$ 4,6-diamindino-2-phenylindole (DAPI) (Sigma). Seedlings were incubated in a glycerin series in wash buffer $(30 \%, 50 \%, 70 \%)$, and the roots were mounted with Citifluor (Ted Pella, Inc., Redding, CA).

Confocal microscopy was with a Zeiss confocal microscope with a helium line at $543 \mathrm{~nm}$. Images were stored as TIFF files, manipulated in ADOBE Photoshop, and printed on a Kodak XL7700 dye sublimation printer.

\section{Molecular techniques}

Isolation of total plant RNA and poly $(\mathrm{A}){ }^{+}$RNA was performed as described (Aeschbacher et al. 1991). RNA was denatured by glyoxal prior to electrophoresis using a denaturing sodium phosphate buffer system (Ausubel et al. 1987). Reverse transcriptase-PCR was performed according to a protocol from Clontech. cDNA was synthesized with the first-strand cDNA synthesis kit (Stratagene) using oligo(dT) as primer. The reaction was then treated with $\mathrm{RNase} H$ to remove the remaining RNA. PCR amplification was carried out with opposing primers complementary to the coding region. These primers flanked introns to distinguish correct cDNA amplification from genomic contamination. The primer pairs map to positions 1637-1661 and 1902-1926 (reverse orientation), 3451-3476 and 4058-4082 (reverse), and 1637-1661 and 2451-2485 (reverse). Amplified products were size separated on agarose gels, and the identity of the fragments was confirmed by Southern hybridization using the $S A B R E$ cDNA as probe. An amplification product of $S A B R E$ mRNA was detectable by ethidium bromide staining only after 41 cycles of amplification, whereas amplification of POSF21 (Aeschbacher et al. 1991), a moderately expressed gene that served as a control, was achieved after 27 cycles.

A genomic library was generated from a partial Sau3A digest of DNA from heterozygous sab1-1 plants and screened with T-DNA probes. One clone was isolated that included the T-DNA left border and adjacent plant sequences. The plant DNA was used to probe genomic DNA from wild-type and mutant plants. An RFLP was observed that confirmed that the sequence was adjacent to the insertion site of the T-DNA. The fragment was then used to rescreen the genomic library. Because the library had been prepared from heterozygous plants, we were able to isolate four overlapping clones that contained the wild-type genomic region. Restriction mapping of these clones showed that they span $\sim 10 \mathrm{~kb}$ on either side of the T-DNA insertion point. To map the transcription start site by RACE, CDNA, synthesized as described, was tailed at the $5^{\prime}$ end with terminal transferase and deoxyguanidine (dG) nucleotides.
PCR reactions were then performed using internal primers and a synthetic oligonucleotide that hybridizes to G-stretches. A second round of amplification was performed on a fraction of the first reaction, using a primer that mapped closer to the $5^{\prime}$ end of the cDNA and a primer complementary to the $5^{\prime}$ end of the tailing primer. The amplified RACE fragment $(\sim 300 \mathrm{bp})$ was blunt-ended with T4 DNA polymerase and kinased with T4 polynucleotide kinase and subcloned. All 10 sequenced products had the same RNA start site although the length of the G-tail varied from 12 to 16 . The internal primers used for this procedure map to positions 235-259 (reverse orientation) and 203-228 (reverse orientation). The SABRE sequence was deposited as a segmented sequence in GenBank under accession numbers U19121-U-19134.

Northern and Southern transfer of RNA and DNA to nylon membranes (GeneScreen Plus, DuPont) and hybridization conditions were as described (Aeschbacher et al. 1991). The dideoxy sequencing method was performed as described (Aeschbacher et al. 1991). Sequencing reactions were also performed using the SequiTherm Cycle sequencing kit from Epicentre. Nested deletions of $S A B R E$ cDNAs were produced according to the "pBluescript Exo/Mung DNA sequencing system" (Stratagene) and sequenced in both directions. Double-stranded miniprep DNA was denatured by alkali treatment, and deletion clones differing by not more than $200 \mathrm{bp}$ apart from each other were sequenced. The genomic sequence was generated by sequencing the plasmid pGRS2, whose genomic DNA insert encompasses the complete wild-type $S A B R E$ gene, with oligonucleotides derived from the cDNA sequence. The 1-bp deletion in sab1-2 was identified by sequencing PCR fragments from amplified genomic DNA of $s a b 1-2$. Two independent PCR reactions with different primers and with DNA from different plants contained the same deletion. The promoter sequence was obtained from a subclone of pGRS2 by sequencing Exo-Mung bean deletion clones from both directions. DNA sequences were analyzed using the "GCG sequence analysis software package" (Devereux et al. 1984).

\section{Acknowledgments}

We thank K. Schultheiss, S. Peng, V. Blanc, J. Martinsons, K. Galagher, and $\mathrm{H}$. Bondar for technical assistance. P. Scolnik kindly mapped the SABRE locus. We thank A. Gash, N.-H. Chua, and J. Ecker for cDNA libraries, J. Ecker for the ein 1 and eto mutants, H. Xerb and J. Canary for synthesizing trans-cyclooctene, Dilip Shah for the basic chitinase clone, S. Hake for providing maize, rice, and barley DNA, G. Tjaden for tobacco DNA, R. White for use of his slide scanner, C. Leonard for help with confocal microscopy, and S. Ruzin for advice and protocols for confocal microscopy. We also thank D. Cosgrove, J. Diller, J. Malamy, I. Martinsons, and K. Galagher for thoughtful suggestions on the manuscript. R.A.A. was supported by a fellowship from the Swiss National Science Foundation. M.-T.H was supported by a Shroedinger fellowship from the Austrian Science Foundation (J0676-MOB). The work in the laboratory of P.N.B. is supported by a grant from the National Institutes of Health (ROl-GM43778).

The publication costs of this article were defrayed in part by payment of page charges. This article must therefore be hereby marked "advertisement" in accordance with 18 USC section 1734 solely to indicate this fact.

\section{References}

Abeles, F.B., P.W. Morgan, and M.E. Saltveit Jr. 1992. Ethylene in plant biology, pp. 147-156. Academic, San Diego, CA. 
Aeschbacher, R.A., M. Schrott, I. Potrykus, and M.W. Saul. 1991. Isolation and molecular characterization of PosF21, an Arabidopsis thaliana gene which shows characteristics of a b-Zip class transcription factor. Plant $J$. 1: 303-316.

Aeschbacher, R.A., J.W. Schiefelbein, and P.N. Benfey. 1994. The genetic and molecular basis of root development. Annu. Rev. Plant Physiol. Plant Mol. Biol. 45: 25-45.

Ausubel, F.M., R. Brent, R.E. Kingston, D.D. Moore, J.G. Seidman, J.A. Smith, and K. Struhl. 1987. Current protocols in molecular biology. John Wiley and Sons, New York.

Baluska, F., R.W. Brailsford, M. Hauskrecht, M.B. Jackson, and P.W. Barlow. 1993. Cellular dimorphism in the maize root cortex: Involvement of microtubules, ethylene and gibberellin in the differentiation of cellular behaviour in postmitotic growth zones. Bot. Acta 106: 394 403.

Baskin, T.I. and R.E. Williamson. 1992. Ethylene, microtubules and root morphology in wild-type and mutant Arabidopsis seedlings. Curr. Top. Plant Biochem. Physiol. 11: 118-130.

Bell, C.J. and J.R. Ecker. 1994. Assignment of 30 microsatellite loci to the linkage map of Arabidopsis. Genomics 18: 137144.

Benfey, P.N. and J.W. Schiefelbein. 1994. Getting to the root of plant development: The genetics of Arabidopsis root formation. Trends Genet. 10: 84-88.

Benfey, P.N., P.J. Linstead, K. Roberts, J.W. Schiefelbein, M.-T. Hauser, and R.A. Aeschbacher. 1993. Root development in Arabidopsis: Four mutants with dramatically altered root morphogenesis. Development 119: 57-70.

Bleecker, A.B., M.A. Estelle, C. Somerville, and H. Kende. 1988. Insensitivity to ethylene conferred by a dominant mutation in Arabidopsis thaliana. Science 241: 1086-1089.

Chang, C., S.F. Kwok, A.B. Bleecker, and E.M. Meyerowitz. 1993. Arabidopsis ethylene-response gene etr1: Similarity of product to two-component regulators. Science 262: 539544.

Devereux, J., P. Haeberli, and O. Smithies. 1984. A comprehensive set of sequence analysis programs for the VAX. Nucleic Acids Res. 12: 387-395.

Dolan, L., K. Janmaat, V. Willemsen, P. Linstead, S. Poethig, K. Roberts, and B. Scheres. 1993. Cellular organization of the Arabidopsis thaliana root. Development 119: 71-84.

Dolan, L., C.M. Duckett, C. Grierson, P. Linstead, K. Schneider, E. Lawson, C. Dean, S. Poethig, and K. Roberts. 1994. Clonal relationships and cell patterning in the root epidermis of Arabidopsis. Development 120: 2465-2474.

Feldmann, K.A. 1991. T-DNA insertion mutagenesis in Arabidopsis: Mutational spectrum. Plant J. 1: 71-82.

Frohman, M.A., M.K. Dush, and G.R. Martin. 1988. Rapid production of full-length cDNAs from rare transcripts: Amplification using a single gene-specific oligonucleotide primer. Proc. Natl. Acad. Sci. 85: 8998-9002.

Giddings, T.H., Jr. and L.A. Staehelin. 1991. Microtubule-mediated control of microfibril deposition: A re-examination of the hypothesis. In The cytoskeletal basis of plant growth and form, (ed. C.W. Lloyd), pp. 85-100. Academic, London, $\mathrm{UK}$.

Guzman, P. and J.R. Ecker. 1990. Exploiting the triple response of Arabidopsis to identify ethylene-related mutants. Plant Cell 2: 513-523.

Hauser, M.-T., A. Morikami, and P.N. Benfey. 1995. Conditional root expansion mutants of Arabidopsis. Development (in press).

Jackson, M.B. 1991. Ethylene in root growth and development. In The plant hormone ethylene (ed. A.K. Mattoo and J.C. Suttle), pp. 159-181. CRC Press, Boca Raton, FL.

Kieber, J.J., M. Rothenberg, G. Roman, K.A. Feldmann, and J.R.
Ecker. 1993. CTR1, a negative regulator of the ethylene response pathway in Arabidopsis, encodes a member of the Raf family of protein kinases. Cell 72: 427-441.

Konieczny, A. and F.M. Ausubel. 1993. A procedure for mapping Arabidopsis mutations using co-dominant ecotype-specific PCR-based markers. Plant I. 4: 403-410.

Kozak, M. 1984. Compilation and analysis of sequences upstream from the translational start site in eukaryotic $\mathrm{mR}$ NAs. Nucleic Acids Res. 12: 857-872.

Leptin, M. 1994. Control of epithelial cell shape changes. Curr. Biol. 4: 709-712.

McLauchlan, J., D. Gaffney, J.L. Whitton, and J.B. Clements. 1985. The consensus sequence YGTGTTYY located downstream from the AATAAA signal is required for efficient formation of mRNA $3^{\prime}$ termini. Nucleic Acids Res. 13: $1347-1368$.

Reiter, R.S., J.G.K. Williams, K.A. Feldmann, J.A. Rafalski, S.V. Tingey, and P.A. Scolnik. 1992. Global and local genome mapping in Arabidopsis thaliana by using recombinant inbred lines and random amplified polymorphic DNAs. Proc. Natl. Acad. Sci. 89: 1477-1481.

Roberts, K. 1989. The plant extracellular matrix. Curr. Opin. Cell Biol. 1: 1020-1027.

Samac, D.A., C.M. Hironaka, P.E. Yallaly, and D.M. Shah. 1990. Isolation and characterization of the genes encoding basic and acidic chitinase in Arabidopsis thaliana. Plant Physiol. 93: 907-914

Snell, V. and P. Nurse. 1993. Investigations into the control of cell form and polarity: The use of morphological mutants in fission yeast. Development (Suppl.) 289-299.

Steeves, T.A. and I.M. Sussex. 1989. Patterns in plant development. Cambridge University Press, Cambridge, UK.

Valvekens, D., M.V. Montagu, and M.V. Lusebettens. 1988. Agrobacterium tumefaciens-mediated transformation of $\mathrm{Ar}$ abidopsis thaliana root explants by using kanamycin selection. Proc. Natl. Acad. Sci. 85: 5536-5540. 


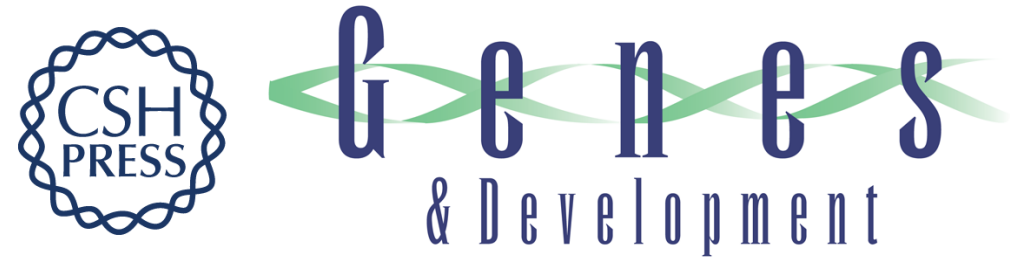

\section{The SABRE gene is required for normal cell expansion in Arabidopsis.}

R A Aeschbacher, M T Hauser, K A Feldmann, et al.

Genes Dev. 1995, 9:

Access the most recent version at doi:10.1101/gad.9.3.330

References This article cites 24 articles, 10 of which can be accessed free at:

http://genesdev.cshlp.org/content/9/3/330.full.html\#ref-list-1

License

Email Alerting

Service

Receive free email alerts when new articles cite this article - sign up in the box at the top right corner of the article or click here.

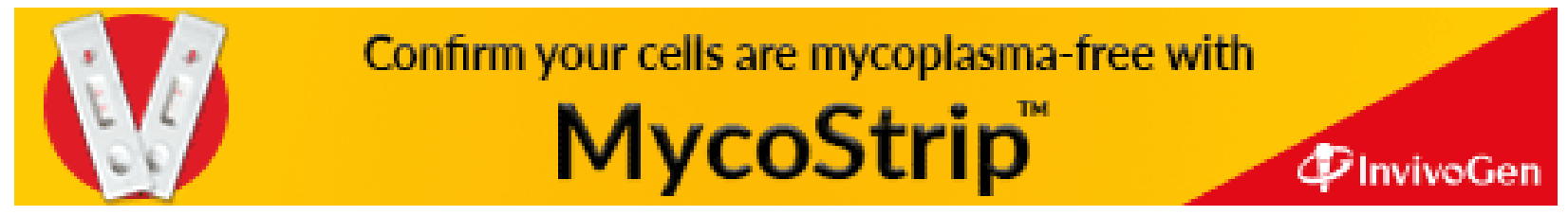

